\section{Pacific Northwest}

National Laboratory

Operated by Battelle for the

U.S. Department of Energy

\title{
Progress Report on the Laboratory Testing of Bulk Vitrification Cast Refractory
}

\author{
E. M. Pierce \\ B. P. McGrail \\ L. M. Bagaasen \\ D. M. Wellman \\ J. V. Crum \\ K. N. Geiszler \\ S. R. Baum
}

November 2004

Prepared for the U.S. Department of Energy under Contract DE-AC06-76RL01830 


\section{DISCLAIMER}

This report was prepared as an account of work sponsored by an agency of the United States Government. Neither the United States Government nor any agency thereof, nor Battelle Memorial Institute, nor any of their employees, makes any warranty, expressed or implied, or assumes any legal liability or responsibility for the accuracy, completeness, or usefulness of any information, apparatus, product, or process disclosed, or represents that its use would not infringe privately owned rights. Reference herein to any specific commercial product, process, or service by trade name, trademark, manufacturer, or otherwise does not necessarily constitute or imply its endorsement, recommendation, or favoring by the United States Government or any agency thereof, or Battelle Memorial Institute. The views and opinions of authors expressed herein do not necessarily state or reflect those of the United States Government or any agency thereof.

\section{PACIFIC NORTHWEST NATIONAL LABORATORY operated by \\ BATTELLE MEMORIAL INSTITUTE for the \\ UNITED STATES DEPARTMENT OF ENERGY under Contract DE-AC06-76RLO 1830}

Printed in the United States of America

$$
\begin{aligned}
& \text { Available to DOE and DOE contractors from the } \\
& \text { Office of Scientific and Technical Information, } \\
& \text { P.O. Box 62, Oak Ridge, TN 37831-0062; } \\
& \text { ph: (865) 576-8401 } \\
& \text { fax: (865) 576-5728 } \\
& \text { email: reports@adonis.osti.gov }
\end{aligned}
$$

Available to the public from the National Technical Information Service,

U.S. Department of Commerce, 5285 Port Royal Rd., Springfield, VA 22161

$$
\begin{aligned}
& \text { ph: (800) } 553-6847 \\
& \text { fax: (703) 605-6900 }
\end{aligned}
$$

email: orders@ntis.fedworld.gov

online ordering: http://www.ntis.gov/ordering.htm 
PNNL-14935

\title{
Progress Report on the Laboratory Testing of Bulk Vitrification Cast Refractory
}

\author{
E. M. Pierce \\ B. P. McGrail \\ L. M. Bagaasen \\ D. M. Wellman \\ J. V. Crum \\ K. N. Geiszler \\ S. R. Baum
}

November 2004

Prepared for

the U.S. Department of Energy

under Contract DE-AC06-76RLO 1830

Pacific Northwest National Laboratory

Richland, WA 


\section{Summary}

The Hanford Site in southeastern Washington State has been used extensively to produce nuclear materials for the U. S. strategic defense arsenal by the U. S. Department of Energy (DOE). A large inventory of radioactive and mixed waste has accumulated in 177 single- and doubleshell tanks. Liquid waste recovered from the tanks will be pre-treated to separate the lowactivity fraction from the high-level and transuranic wastes. Currently, the DOE Office of River Protection (ORP) is evaluating several options for immobilization of low-activity tank wastes for eventual disposal in a shallow subsurface facility at the Hanford Site. A significant portion of the waste will be converted into immobilized low-activity waste (ILAW) glass with a conventional Joule-heated ceramic melter. In addition to ILAW glass, supplemental treatment technologies are under consideration by the DOE to treat a portion of the low activity waste. The reason for using a supplemental treatment technology is to accelerate the overall cleanup mission at the Hanford site. In late 2003, ORP's tank farm contractor, CH2M HILL Hanford Group, Inc. (CH2M HILL), made the decision to enter into contract negotiations with AMEC Earth and Environmental, Inc. for a pilot supplemental treatment test and demonstration facility that employs a bulk vitrification (BV) technology.

Work in FY03 on engineering and large scale tests of the BV process suggested that a small portion of the waste stream ${ }^{99} \mathrm{Tc}$ inventory would end up in a soluble form deposited in a vesicular glass layer located at the top of the BV melt and in the sand used as an insulator after vitrification. In the FY03 risk assessment (RA) (Mann et al. 2003), the soluble Tc salt in the BV waste packages creates a ${ }^{99} \mathrm{Tc}$ concentration peak at early times in the groundwater extracted from a 100-meter down-gradient well. This peak differs from the presently predicted baseline WTP glass performance, which shows an asymptotic rise to a constant release rate. Because of the desire by regulatory agencies to achieve essentially equivalent performance to WTP glass with supplemental treatment technologies, the BV process was modified in FY04 in an attempt to minimize deposition of soluble ${ }^{99} \mathrm{Tc}$ salts by including a castable refractory block (CRB) in place of a portion of the refractory sand layer and using a bottom-up melting technique to eliminate the vesicular glass layer at the top. However, the refractory block is still porous and there is the potential for leachable ${ }^{99} \mathrm{Tc}$ to deposit in the pores of the CRB.

The purpose of this progress report is to document the status of a laboratory testing program being conducted at Pacific Northwest National Laboratory (PNNL) for CH2M HILL in support of the LAW Supplemental Treatment Technologies Demonstration project. The objective of these tests was to provide an initial estimate of the leachable fraction of key contaminants of concern (Cs, Re [chemical analogue for $\left.{ }^{99} \mathrm{Tc}\right]$, and ${ }^{99} \mathrm{Tc}$ ) that could condense within the BV CRB. Contained in this progress report are results on the soluble fraction of Re (chemical analogue for ${ }^{99} \mathrm{Tc}$ ) from two non-radioactive tests (ES-31A and ES-31B) and one test using a ${ }^{99} \mathrm{Tc}$ spike (ES-32A). Soluble ${ }^{99} \mathrm{Tc}$ was determined for ES-32A, and soluble Cs was determined for ES-31B. In these dynamic ES tests, several factors contribute to the deposition of Re and/or ${ }^{99} \mathrm{Tc}$ on the $\mathrm{CRB}$ and box lid. These factors include: 1) horizontal and vertical temperature gradients in the CRB, 2) air-flow, 3) physical and chemical changes in the CRB, and 4) mineralogical phase changes the $\mathrm{CRB}$ undergoes during the $\mathrm{BV}$ process. Results from the individual ES tests suggest the following with regard to ${ }^{99} \mathrm{Tc}$ deposition into the pores of the CRB 1) deposition into the pores of the CRB is probably occurring by vapor phase transport and molten salt intrusion, although the rate-limiting mechanism is not clear and 2) Cs, Re, and ${ }^{99} \mathrm{Tc}$ are being deposited in the CRB in a leachable form. This information will be used to assess progress to 
date and guide development of additional modifications to the BV process to further reduce the soluble ${ }^{99}$ Tc levels in the BV waste package, as necessary. 


\section{Contents}

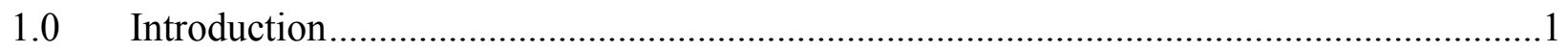

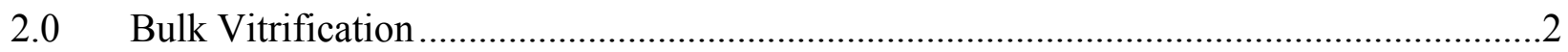

3.0 Experimental Materials and Methods ...................................................................

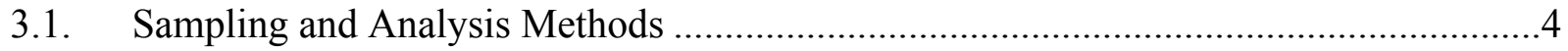

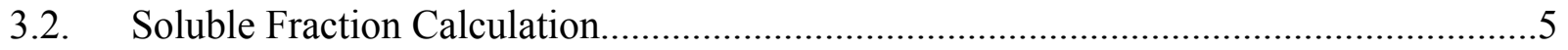

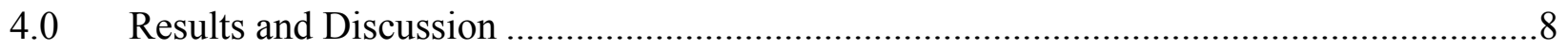

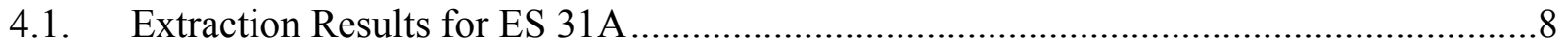

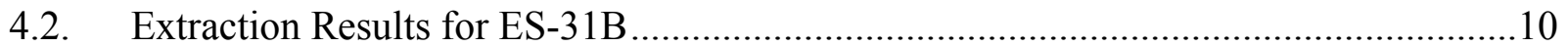

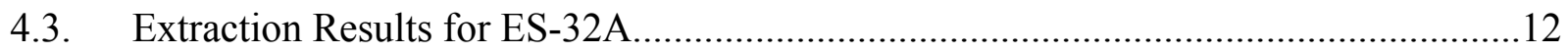

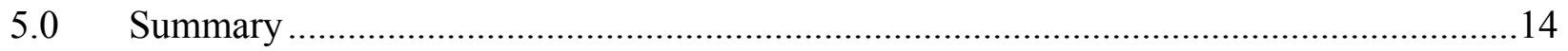

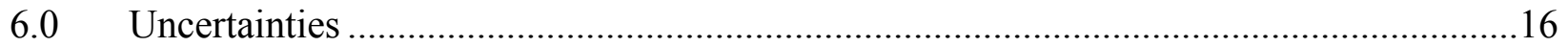

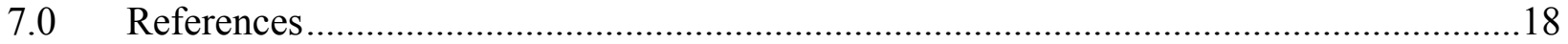

8.0 Appendix A: Soluble Fraction Error Calculation …...................................................20 


\section{Figures}

Figure 1. SEM Image of the Castable Refractory.................................................................. 2

Figure 2. Plan View of the ES-BV Design. ................................................................... 3

Figure 3. Schematic of the BV Sampling Plan. All Values shown in inches. ........................... 4

Figure 4. Schematic of the Engineering Scale BV Design. ................................................... 6

Figure 5. Photo of a refractory sample from ES-31A BV waste package ................................ 8

Figure 6. Re distribution as a function of depth for sample EST-04-01.................................. 8

Figure 7. Re distribution as a function of depth for Thin Sections from ES-31B. .................. 10

Figure 8. Summary of ES-31A, -31B, and -32A Extraction Results...................................... 14 


\section{Tables}

Table 1. Estimated Starting Inventory for ES-31A, ES-31B, and ES-32A. ............................ 7

Table 2. Soluble Fraction of Re contained in ES-31A......................................................... 9

Table 3. Soluble Fraction of Re and Cs contained in ES-31B............................................... 11

Table 4. Soluble Fraction of Re and ${ }^{99} \mathrm{Tc}$ contained in ES-32A........................................... 13

Table 5. List of Relative Uncertainties for Measure Quantities ............................................. 21 


\section{Quality Assurance}

The work described in this report was performed under the PNNL Nuclear Quality Assurance Requirements Description (NQARD) procedures in accordance with the Supplemental Treatment Technologies Support Program, Tank Waste Support Quality Assurance Plan Rev. 6. These project quality assurance procedures and the project QA plan are compliant with the national standard ASME/NQA-1 as required in the project sponsor's statement of work. Testing documented in this report was performed in accordance with Test Plan: "Cast Refractory Extraction Technique," 46611-2004-01, Rev.0. 


\section{ACRONYMS}

$\begin{array}{ll}\text { ASME } & \text { American Society of Mechanical Engineers } \\ \text { ASTM } & \text { American Society for Testing and Materials } \\ \text { BV } & \text { bulk vitrification } \\ \text { CS } & \text { cast stone } \\ \text { CRB } & \text { castable refractory block, comprised of a mullite material } \\ \text { DIW } & \text { deionized water } \\ \text { DOE } & \text { U.S. Department of Energy } \\ \text { ES } & \text { engineered scale } \\ \text { EST } & \text { engineered scale test } \\ \text { HLW } & \text { high-level waste } \\ \text { ICP-OES } & \text { inductively coupled plasma optical emission spectrometry } \\ \text { ICP-MS } & \text { inductively coupled plasma mass spectrometry } \\ \text { IDF } & \text { integrated disposal facility } \\ \text { ILAW } & \text { immobilized low activity waste } \\ \text { LAW } & \text { low-activity waste } \\ \text { NQARD } & \text { nuclear quality assurance requirements document } \\ \text { ORP } & \text { Office of River Protection } \\ \text { PA } & \text { performance assessment } \\ \text { PNNL } & \text { Pacific Northwest National Laboratory } \\ \text { QA } & \text { quality assurance } \\ \text { RA } & \text { risk assessment } \\ \text { rpm } & \text { revolutions per minute } \\ \text { SAP } & \text { sampling and analysis plan } \\ \text { SR } & \text { steam reformation } \\ \text { WTP } & \text { Waste Treatment Plant } \\ & \end{array}$




\subsection{Introduction}

The accelerated cleanup mission is a strategic initiative for acceleration of tank waste treatment by increasing the capacity of the WTP and using supplemental technologies for waste treatment and immobilization for as much as $70 \%$ of the low-activity waste (LAW) (DOE 2002). Three supplemental treatment technology options (bulk vitrification [BV], steam reformation [SR], and cementation or cast stone [CS]) were evaluated in 2003 for the immobilization of lowactivity tank waste. Detailed discussions of the preliminary risk assessment (RA) results are included in Mann et al. (2003). These results helped to identify bulk vitrification as a potential supplemental treatment technology that can be used to treat LAW at Hanford. The use of this supplemental waste form would help DOE meet the long-term groundwater protection criteria for the disposal of waste in a shallow land burial facility. Before WTP glass and a supplemental waste form can be disposed, DOE must approve a performance assessment (PA). The PA document describes the long-term impacts of the disposal facility on public health and environmental resources.

Work in FY03 on engineering and large scale tests of the BV process suggested that approximately $0.3 \mathrm{wt} \%$ of the ${ }^{99} \mathrm{Tc}$ inventory in the waste stream would end up in a soluble form deposited in a vesicular glass layer located at the top of the BV melt ${ }^{1}$. Additional analysis and extrapolation of the FY03 engineering and large scale tests indicate that as much as $3 \mathrm{wt} \%$ of the ${ }^{99} \mathrm{Tc}$ inventory waste stream may have ended up in the sand insulation layer after vitrification ${ }^{2}$. In the FY03 RA (Mann et al. 2003), the soluble Tc salt in the BV waste packages creates a ${ }^{99} \mathrm{Tc}$ concentration peak at early times in the groundwater extracted from a 100-meter down-gradient well ${ }^{3}$. This peak differs from the presently predicted baseline WTP glass performance, which shows an asymptotic rise to a constant release rate. Because of the desire by regulatory agencies to achieve essentially equivalent performance to WTP glass with supplemental treatment technologies, the BV process was modified in FY04 in an attempt to minimize deposition of soluble ${ }^{99} \mathrm{Tc}$ salts by including a CRB in place of a portion of the refractory sand layer and using a bottom-up melting technique to eliminate the vesicular glass layer at the top.

This letter report focuses on estimation of the soluble fraction of ${ }^{99} \mathrm{Tc}$ that exists in the castable refractory block and sand components used in the current BV process. Additional testing is in progress to provide the required input parameters to conduct PA calculations (McGrail et al. 2003a). Results from these tests will be provided in a separate report.

Technetium and its chemical analog Re are volatile elements when in the +7 oxidation state and exposed to high temperatures, such as during vitrification processes (Darab and Smith 1996). Although glass temperatures in the BV process have not been measured, temperatures as high as $1500^{\circ} \mathrm{C}$ may be experienced in some portions of the melt. These high process temperatures are thought to drive vaporization of Tc-bearing salts from the glass melt and also from radiative

\footnotetext{
${ }^{1}$ The value of $0.3 \mathrm{wt} \%$ of the waste stream ${ }^{99} \mathrm{Tc}$ was calculated from the mass of soluble rhenium (Re, chemical analogue for ${ }^{99} \mathrm{Tc}$ ) found in the vesicular glass layer from a non-radioactive large-scale BV test, adjusted for a measured volatilization ratio between ${ }^{99} \mathrm{Tc}$ and Re from engineering-scale testing (McGrail et al., 2003b).

${ }^{2}$ The higher value of $3 \mathrm{wt} \%$ is extrapolated from engineering scale data where soluble ${ }^{99} \mathrm{Tc}$ and Re were measured in the refractory sand. Actual data for soluble Re in the refractory sand of the non-radioactive large-scale BV test are not available.

${ }^{3}$ The FY03 risk assessment used $0.3 \mathrm{wt} \%$ of the waste stream ${ }^{99} \mathrm{Tc}$.
} 
heating of the waste feed prior to physical incorporation in the glass. The volatilized salts are subject to vaporphase condensation when they contact cooler surfaces. Characterization results on the vesicular glass layer found in FY03 test specimens, prior to altering the BV waste immobilization process, identified a white coating that is partially made up of $\mathrm{KReO}_{4}$. Although changing to a CRB from quartz sand in the new BV process significantly reduced the overall porosity and permeability of the insulation layer, the CRB is still porous and also has a much higher relative surface area (see Figure 1) as compared with quartz sand where volatilized rhenium (Re) and technetium $\left({ }^{99} \mathrm{Tc}\right)$ bearing soluble salts can condense. Although ${ }^{99} \mathrm{Tc}$ is assumed to volatilize, migrate, and condense in an analogous manner in the CRB forming a soluble $\mathrm{KTcO}_{4}$ salt, $\mathrm{KTcO}_{4}$ has not been positively identified as a discrete phase in the $\mathrm{BV}$ process.

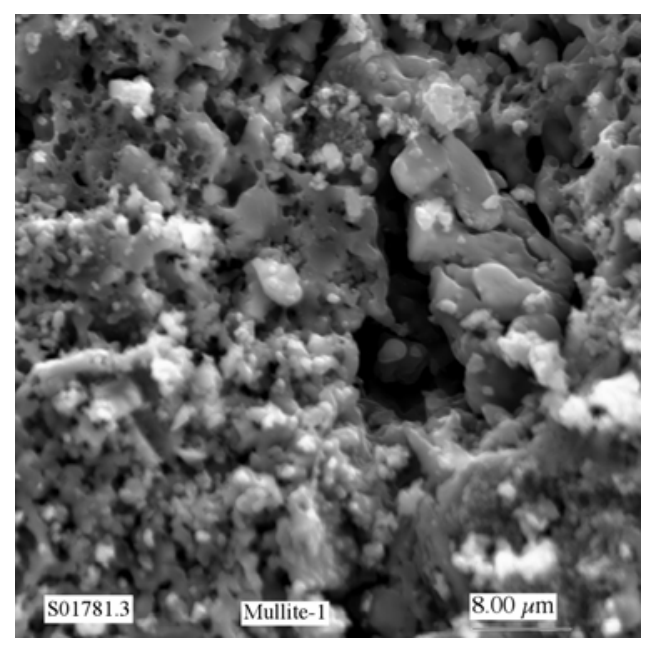

Figure 1. SEM Image of the Castable Refractory.

This letter report describes the progress of a laboratory-testing program performed at Pacific Northwest National Laboratory (PNNL) in support of the LAW Supplemental Treatment Technologies Demonstration project. This report discusses the methods used and results obtained to determine the fraction of cesium $(\mathrm{Cs}), \mathrm{Re}$, and ${ }^{99} \mathrm{Tc}$ that has volatilized, migrated, and condensed into the castable refractory block and/or sand layers for three engineering-scale tests (EST).

\subsection{Bulk Vitrification}

Bulk vitrification (AMEC Earth \& Environmental, Inc.) is a modification of the in-situ vitrification (ISV) process developed for remediation of buried wastes and contaminant plumes in soil (Luey and Seiler 1995; Tixier 1991). An in-container vitrification process has been designed in which low-activity waste, soil, and glass forming chemicals are mixed, dried, and then melted at approximately $1500^{\circ} \mathrm{C}$ by electrical resistance (Kim et al. 2003). Graphite flakes are added to the mix to form a conductive path for melt initiation. Electrical current is supplied by two graphite electrodes imbedded in the batch. After melt initiation, waste is gradually loaded in increments until the box is filled with waste glass. The current full-scale BV design uses steel containers that are $8 \mathrm{ft}$ (tall) $\times 8 \mathrm{ft}($ high $) \times 24 \mathrm{ft}$ (long), which is considerably larger than the engineering scale (ES) design. Refractory material is used to insulate the steel container walls from the high-temperature glass melt. Starting at the glass/castable refractory block interface and moving toward the outer wall of the steel container, the layers include a $15.2 \mathrm{~cm}(6 \mathrm{in})$ cast refractory, $10.2 \mathrm{~cm}(4 \mathrm{in})$ of quartz sand and a $5.1 \mathrm{~cm}$ (2 in) layer of duraboard insulation. Although a general description of the overall BV process is given above, for a more detailed description an interested reader should consult Sederburg and Thompson (2004). 


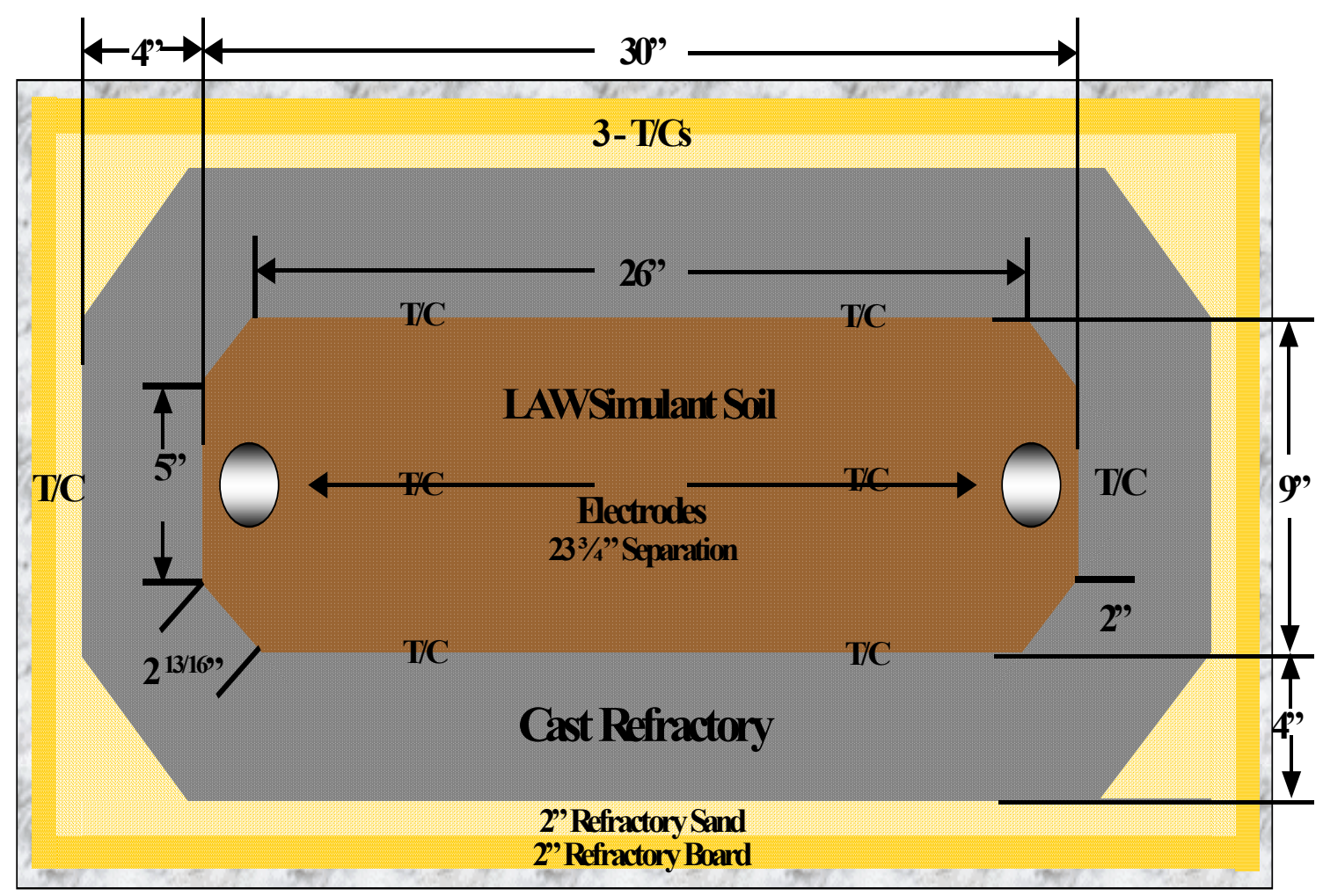

Figure 2. Plan View of the ES-BV Design.

To gather information on the full-scale configuration, 1/6th linear scale ES tests were conducted. In these tests, the high-temperature glass melt was kept insulated from the steel container by lining the container walls with a $10.2 \mathrm{~cm}(4 \mathrm{in})$ cast refractory block, $5.1 \mathrm{~cm}(2 \mathrm{in})$ of quartz sand, a $5.1 \mathrm{~cm}$ ( 2 in) layer of duraboard insulation. The temperature condition for each test was monitored using thermocouples $(\mathrm{T} / \mathrm{C})$ that were distributed throughout the glass, cast refractory block, and sand portions of the BV waste package. A schematic plan view of the engineered scale BV waste package configuration is shown in Figure 2. The current technique of loading waste incrementally over time has eliminated the vesicular glass layer observed in previous BV waste package designs (McGrail et al. 2003b). Although the vesicular glass layer has been eliminated, the waste package cannot be represented by a single set of physical and chemical properties. The package is heterogeneous with complex interfaces. Therefore, the BV product is divided into four distinct components: 1) bulk glass, 2) mullite cast refractory, 3) sand layer, and 4) off-gas fume hood. Additional divisions could be assigned but these three components are believed to adequately represent the most significant features of the final BV product. Sampling and analysis of condensed salts on the fume hood is being done by AMEC, Inc. and is not covered in this letter report. 


\subsection{Experimental Materials and Methods}

Three engineered-scale tests; ES-31A, -31B, and -32A, were sampled to determine the waterextractable Cs, Re, and/or ${ }^{99} \mathrm{Tc}$ fractions contained in the CRB and sand layers. The techniques and procedures used to sample and analyze the BV cast refractory are described below. Note the sampling and analysis plan discussed below was not statistically designed. Also, all error values reported are $1 \sigma$ uncertainties, unless other wise noted. A grab sampling approach was used to remove representative samples of the five vertical depths, which were used to estimate the soluble fraction of Cs, Re, and ${ }^{99} \mathrm{Tc}$ in the CRB for each ES test. For a detail discussion of the sampling and analysis plan (SAP) for the BV waste package the interested reader should consult Sederburg and Thompson (2004).

\subsection{Sampling and Analysis Methods}

Several samples of cast refractory were removed using an electric jackhammer and broken into the appropriate size for the equipment used in the extraction. The approximate sampling locations are illustrated in Figure 3. Each sample had an approximate height of 2 inches and penetrated through the full 4 -inch thickness of the refractory wall. Figure 3 also illustrates that cast refractory was sampled at 6 points and 5 vertical depths ranging between 3 and 5 inches for a total of 30 samples. Note the 6 points represent the sample locations for each of the 5 vertical depths. In addition to these 30 samples, at least 1 additional sample was taken from the bottom of each engineered scale (ES) test castable refractory block. Due to time and resource constraints, approximately 5 to 10 of the 31 samples were used in the extraction set.

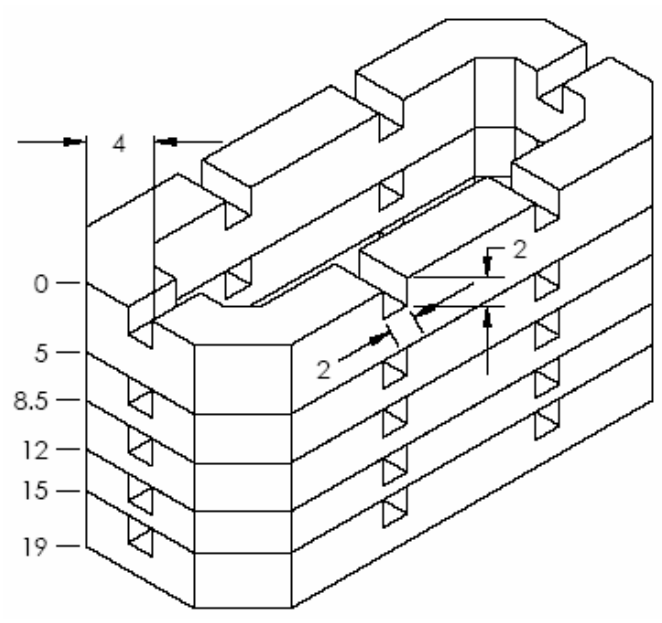

Figure 3. Schematic of the BV Sampling Plan. All Values shown in inches.

For ES-31B, one additional refractory sample from the upper portion was further subdivided into five sub-samples, starting at the glass/cast refractory block interface and extending the full 4 in. to the outer wall of the refractory block. Each sub-sample was approximately $0.7 \mathrm{in}$. thick and under went the same extraction process described below.

In general, each fragment of dry refractory material was weighed, placed into a known volume of leaching solution, and vacuum saturated at a pressure of $84.6-\mathrm{kPa}\left(12.3-1 \mathrm{~b} \mathrm{in} .^{-2}\right)$ for no less than four hours. Deionized water (DIW) was used as the leaching solution for ES-31A and $0.001 \mathrm{M}$ nitric acid $\left(\mathrm{HNO}_{3}\right)$ as an extraction solution for all other ES tests. After saturating each sample, an aliquot of the saturation solution was removed for analysis. The sample fragment was lifted out of the saturation solution and allowed to drip dry so there was no free liquid. As part of the second step in the extraction, the refractory sample was spun between 2000 and 5000 revolutions per minute (rpm) in a centrifuge for one hour to release non-gravity drainable pore liquid. A sample of the centrifuge-extracted liquid was collected for each fragment. The twopart extraction process (saturation and centrifugation) was repeated until the majority of the 
soluble Cs, Re, and/or ${ }^{99} \mathrm{Tc}$ was leached from each sample, typically accomplished with five consecutive two part extractions. ${ }^{4}$ The solution composition from each extract was determined by analyzing for $\mathrm{Cs}, \mathrm{Re}$, and ${ }^{99} \mathrm{Tc}$ analyzed via inductively-coupled plasma-mass spectrometry (ICP-MS).

In addition to DIW and $0.001 \mathrm{M} \mathrm{HNO}_{3}$, a solution that was saturated with respect to the alumino-silicate mineral Nosean, $\mathrm{Na}_{8}\left(\mathrm{Al}_{6} \mathrm{Si}_{6} \mathrm{O}_{24}\right) \mathrm{SO}_{4}$, were used in a few of the ES-31A extrations The Nosean saturated solution was chosen because initial X-ray diffraction (XRD) patterns, not shown here, of the ES-31A refractory suggested that a Nosean phase was present. Previous research by McGrail et al (2003b) conducted on the steam reformer material, illustrated that release of Re was controlled by the dissolution of Nosean. Therefore to determine whether Re was being sequestered by this phase in the BV test, a Nosean saturated solution was used in the extraction process. The composition of this solution was computed using EQ3NR (Wolery 1992) and setting the equilibrium $\mathrm{pH}$ equal to 10. Extraction tests using the Nosean saturated solution showed no significant difference in the quantity of leachable Re suggesting that Re was not associated with a Nosean phase.

\subsection{Soluble Fraction Calculation}

An estimate of the total mass of $\mathrm{Cs}, \mathrm{Re}$, and/or ${ }^{99} \mathrm{Tc}$ that could be dissolved and leached as a soluble salt from the BV cast refractory block was calculated as described in this section.

The mass of contaminant (i.e., Cs, Re, and/or ${ }^{99} \mathrm{Tc}$ ) extracted was computed for each sample fragment, based on the measured concentrations of the element in each extraction sample as well as the volume of solution used to saturate the sample and the volumes extracted from the refractory sample, using Equation (1).

$$
m_{i, k, p, q}=\sum_{n=1}^{N_{e x t, k, p, q}} C_{i, k, p, q, n} V_{k, p, q, n}
$$

where $m_{i, k, p, q}$ is the mass of the $i^{\text {th }}$ species for the $q^{\text {th }}$ fragment of the $p^{\text {th }}$ sample from the $k^{\text {th }}$ section (i.e., horizontal slice) of the refractory $(\mathrm{g}), C_{i, k, p, q, n}$ is the concentration of the $i^{\text {th }}$ specie in the $n^{\text {th }}$ extraction for the $q^{\text {th }}$ fragment of the $p^{\text {th }}$ sample from the $k^{\text {th }}$ section of the refractory $\left(\mathrm{g} \mathrm{L}^{-1}\right.$ ), and $V_{k, p, q, n}$ is the volume of solution that was either used to saturate or extracted from the $q^{\text {th }}$ fragment of the $p^{\text {th }}$ sample from the $k^{\text {th }}$ section of the refractory (L).

\footnotetext{
${ }^{4}$ Unpublished results from a scoping test using a $50 \mathrm{ppb}$ Re stock solution showed that $>80 \%$ of the total extractable Re was removed after three consecutive extractions.
} 
The refractory was separated into 5 horizontal slices as shown in Figure 3. The bottom horizontal slice included the entire base of the refractory and had approximated dimension of 38 in. long $\times 17$ in. wide $\times 4$ in. thick. The other four slices form rectangular rings of the refractory wall with outer dimensions of 38 in. long $\times 17$ in. wide and a wall thickness of 4 inches. The thickness of these slices varied from 2 to 5 inches. The $x y z$ coordinates for each sample are provided in tables contained in the results section. The corresponding zero points for the $x y z$ coordinates are $x$ begins on the exhaust side at the sand/cast refractory interface, $y$ begins at the sand/cast refractory

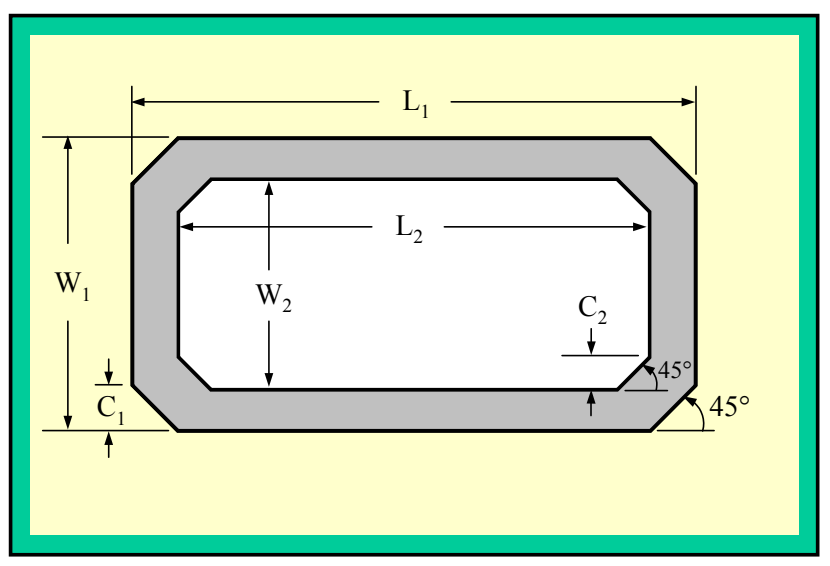

Figure 4. Schematic of the Engineering Scale BV Design. block interface front, and $z$ begins at the vertical top of the cast refractory block. For samples that were broken into fragments, the specific extractable mass of each sample, $\beta_{i, k, p}$, can be calculated using

$$
\begin{gathered}
m_{\text {refract }, k, p}=\sum_{q=1}^{N_{\text {fragment }, k, p}} m_{\text {refract }, k, p, q, l} \\
m_{i, k, p}=\sum_{q=1}^{N_{\text {fragment }, k, p}} m_{i, k, p, q} \\
\beta_{i, k, p}=\frac{m_{i, k, p}}{m_{\text {refract }, k, p}}
\end{gathered}
$$

Equations (2) through (4) where $N_{\text {fragment, } k, p}$ is the number of fragments in the $p^{\text {th }}$ sample of the $k^{\text {th }}$ section. Note that $\beta_{i, k, p}$ is not calculated as an average of the fragment concentrations because the concentration profile from the inner side of the refractory wall to the outer side is not expected to be constant. Each sample spans the entire width of the refractory wall, thus $\beta_{i, k, p}$ represents the specific mass of the $i^{\text {th }}$ specie per unit mass of refractory if the mass of the $i^{\text {th }}$ specie were uniformly distributed within the refractory. It should be noted here that if a sample was not broken into separate fragments for extraction and analysis, then Equation (1) can be used (after dropping all of the $q$ subscripts) to obtain the values for $m_{i, k, p}$ to plug into Equation (4). Equation (2) would be unnecessary when the sample is not broken into fragments because $m_{\text {refract, } k, p}$ is measured directly. The average specific extractable mass for each section can be calculated using

$$
\beta_{i, k}=\frac{\sum_{p=1}^{N_{\text {samples }, k}} \beta_{i, k, p}}{N_{\text {samples }, k}}
$$

where $N_{\text {samples, } \mathrm{k}}$ is the number of samples in the $k^{\text {th }}$ section. 
The volume of each section of the refractory, Equation (8) and (9), can be calculated from the length dimensions $\left(L_{1}, L_{2}, W_{1}, W_{2}, C_{1}\right.$, and $\left.C_{2}\right)$ shown in Figure 2 and Figure 4 . The volume for the base section is only based on the area that is exposed to the melt, assuming that contaminant migration into the "corners" of the base section is negligible. The factor 61.024 converts from in $^{3}$ to liters $(L)$, assuming all length dimensions are in inches.

$$
\begin{gathered}
A_{\text {outer }}=L_{1} W_{1}-2 C_{1}^{2} \\
A_{\text {inner }}=L_{2} W_{2}-2 C_{2}^{2} \\
V_{k}=\frac{\left(A_{\text {outer }}-A_{\text {inner }}\right) H_{k}}{61.024}, \text { for sections in the refractory wall }(k=1 \text { to } 4) \\
V_{k}=\frac{A_{\text {inner }} H_{k}}{61.024}, \text { for the base section }(k=5)
\end{gathered}
$$

The estimated total mass of contaminant that could leach from each segment, $m_{i, k}(\mathrm{~g})$, can be calculated by using the results from Equations 7, 8, and 9, along with the refractory density, $\rho_{\text {refract }}\left(\mathrm{g} \mathrm{L}^{-1}\right)$, and is given by

$$
m_{i, k}=\beta_{i, k} V_{k} \rho_{\text {refract }}
$$

The fraction of the total contaminant mass in the waste material that is extractable from a given section of the refractory material, $f_{i, k}$ (unitless), can be calculated using

$$
f_{i, k}=\frac{m_{i, k}}{m_{\text {total }, i}}
$$

which makes use of the known contaminant inventory for each test, $m_{\text {total, }}(\mathrm{g})$. These starting inventories are listed in Table 1 for each of the three ES tests; ES-31A, ES-31B, and ES-32A (Kim et al. 2004). Finally, the fraction of extractable contaminant mass for the entire system is given by

$$
f_{\text {total }, i}=\sum_{k=1}^{N_{\text {section }}} f_{i, k}
$$

where $f_{\text {total,i }}$ is the sum for all $N_{\text {section }}$ number of sections. A detailed list of the equations used to compute the errors associated with Equations (1) thru (12) are provided in Appendix A.

Table 1. Estimated Starting Inventory for ES-31A, ES-31B, and ES-32A.

\begin{tabular}{ccccccc}
\hline & & & \multicolumn{3}{c}{ Estimated Starting Inventory (g) ${ }^{\mathbf{a}}$} \\
AMEC ID & PNNL ID & Test ID & Re & Cs & ${ }^{\mathbf{9 9}} \mathbf{T c}$ \\
\hline ES-10 & ES-31A & EST-04 thru 06 & 7.7151 & - & - \\
ES-11 & ES-31B & EST-07 thru 09 & 0.4126 & 0.2600 & - \\
ES-12 & ES-32A & EST-10 & 7.5103 & - & 0.3816 \\
\hline avalues from Kim et al., (2004) & \multicolumn{4}{c}{} \\
\hline
\end{tabular}




\subsection{Results and Discussion}

Each of the following sections presents the results of extractions conducted on cast refractory samples taken from each engineering scale test; ES-31A, $-31 \mathrm{~B}$, and -32A. It is important to note that a recent baseline extraction, conducted in November 2004, on a sample of untreated CRB resulted in a measured Re background concentration of $0.5 \mu \mathrm{g} \mathrm{L}^{-1}$. Although this observed Re background concentration is significantly lower than majority of the extraction samples it may impact these results. Currently, additional untreated CRB samples are being extracted to quantify the average Re background concentration. Once completed, all of the data presented in this progress report will be background corrected and the revised values will be listed in a report to be issued in December 2004.

\subsection{Extraction Results for ES 31A}

Fourteen samples of the cast refractory from the ES-31A test were used to determine the percentage of Re that is water-soluble. Each sample was fractured into fragments; water saturated, and extracted using the techniques described above in Section 3.1.

Figure 5 shows a photo of an ES-31A sample, EST-04-01, collected from the back quarter of the refractory near the exhaust hood and electrode. This sample was broken into 5 individual fragments, corresponding to the entire 4 in. thickness of the refractory block from the glass-refractory interface to the sand-refractory interface. A plot

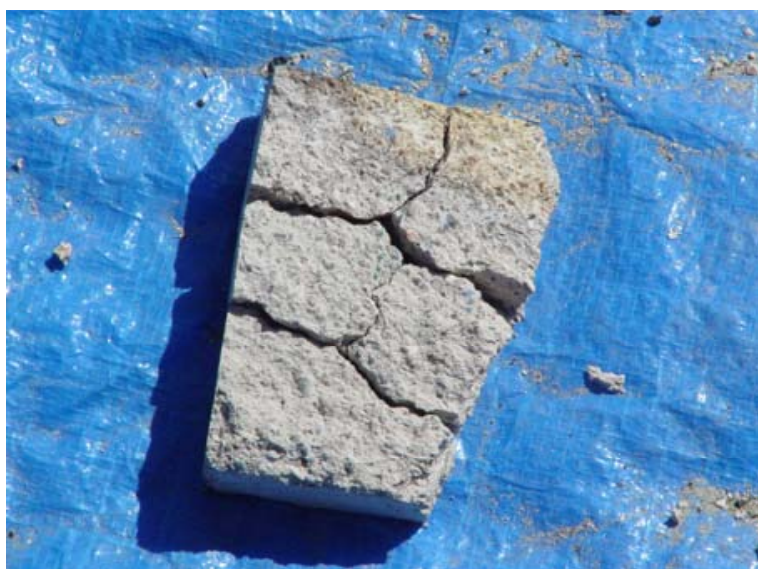

Figure 5. Photo of a refractory sample from ES-31A BV waste package of the specific mass of Re extracted from each fragment illustrates the Re concentration decreases by several orders of magnitude with increasing distance away from the glass melt (Figure 6). These results suggest that the majority of Re is condensing within the first inch of depth beyond the mullite/glass interface.

The extracted Re mass for each fragment was summed and then divided by the total mass of the refractory sample to determine the mass fraction of soluble Re in the entire refractory sample.

Table 2 shows the percent of the total Re in the test system that was extractable from each of the five sections in the ES-31A refractory block. Applying Equations (1) through (12) and using a total Re test inventory of $7.7151 \mathrm{~g}$, the soluble Re fraction present in the refractory was 1.514 $\pm 0.151 \%$. Additional chemical analysis of the extraction solutions, using ICP-OES, illustrate that the major dissolved components were $\mathrm{Al}, \mathrm{Ca}, \mathrm{Na}$, and $\mathrm{S}$; with lesser amounts of $\mathrm{B}, \mathrm{Li}, \mathrm{K}$, and $\mathrm{Si}$.

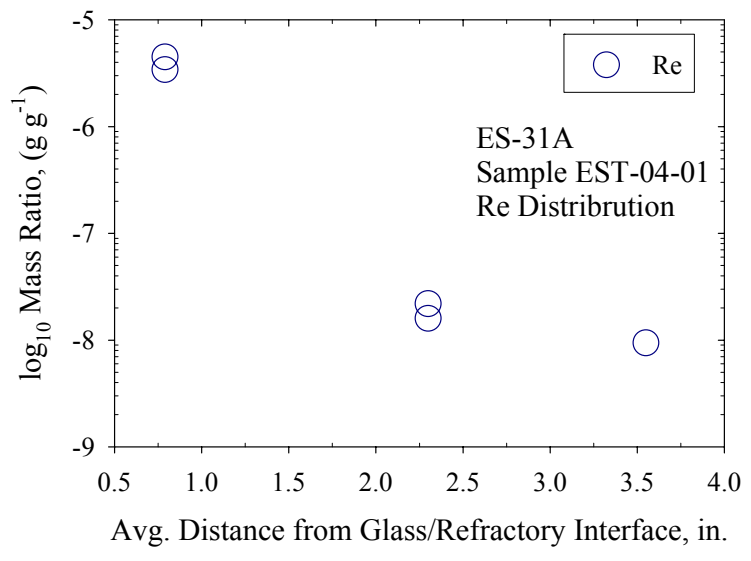

Figure 6. Re distribution as a function of depth for sample EST-04-01. 
The results shown in Table 2; where approximately $84 \%$ of the soluble Re is contained in the upper two sections of the refractory block, combined with the results shown in Figure 6 and the ICP-OES analysis of the extraction solutions suggest that Re transport occurs either as a molten salt and/or as a gas phase salt.

Table 2. Soluble Fraction of Re contained in ES-31A.

\begin{tabular}{|c|c|c|c|c|c|c|c|}
\hline \multicolumn{5}{|c|}{ Section \#1, 0 to 5 in. from the top } & \multicolumn{3}{|c|}{$\mathbf{R e}$} \\
\hline Sample ID & $\mathrm{X}$, in & $\mathrm{Y}$, in & $Z$, in & $\mathrm{H}_{\mathrm{k}}$, in. & ${ }^{\mathrm{a}} \beta_{\mathrm{i} k \mathrm{p}}$ & & \\
\hline EST-04-01 & 8 & 2 & 0 & 5 & $1.87 \mathrm{E}-06$ & & \\
\hline EST-05-01 & 8 & 15 & 0 & 5 & $3.23 \mathrm{E}-07$ & & \\
\hline \multirow[t]{3}{*}{ EST-06-04 } & 28 & 15 & 0 & 5 & $1.25 \mathrm{E}-07$ & & \\
\hline & & & & & ${ }^{\mathrm{a}} \beta_{\mathrm{ik}}$ & ${ }^{{ }^{b}} f_{\text {i_k }}$ & $\bar{~}{ }^{\mathrm{b}} \sigma_{\mathrm{f}_{\mathrm{i} i k}}$ \\
\hline & & & & & $7.73 \mathrm{E}-07$ & $0.838 \%$ & $\pm 0.130 \%$ \\
\hline \multicolumn{5}{|c|}{ Section \#2, 5 to 8.5 in. from the top } & \multicolumn{3}{|c|}{$\operatorname{Re}$} \\
\hline Sample ID & $X$, in & $\mathrm{Y}$, in & $\mathrm{Z}$, in & $\mathrm{H}_{\mathrm{k}}$, in. & $\beta_{\text {i } \_\_p}$ & & \\
\hline EST-04-02 & 8 & 2 & 5 & 3.5 & $1.09 \mathrm{E}-06$ & & \\
\hline \multirow[t]{3}{*}{ EST-05-02 } & 8 & 15 & 5 & 3.5 & $6.99 \mathrm{E}-08$ & & \\
\hline & & & & & $\beta_{\mathrm{i} k}$ & $f_{-\mathrm{i} \_\mathrm{k}}$ & $\sigma_{\mathrm{f}_{\mathrm{i} i \mathrm{k}}}$ \\
\hline & & & & & $5.78 \mathrm{E}-07$ & $0.439 \%$ & $\pm 0.073 \%$ \\
\hline \multicolumn{5}{|c|}{ Section $\# 3,8.5$ to 12 in. from the top } & \multicolumn{3}{|c|}{$\mathbf{R e}$} \\
\hline Sample ID & $\mathrm{X}$, in & $\mathrm{Y}$, in & $Z$, in & $\mathrm{H}_{\mathrm{k}}$, in. & $\beta_{\mathrm{ikp}}$ & & \\
\hline EST-04-05 & 8 & 2 & 9 & 3.5 & $1.81 \mathrm{E}-07$ & & \\
\hline EST-04-09 & 0 & 2 & 9 & 3.5 & $1.06 \mathrm{E}-07$ & & \\
\hline EST-04-10 & 19 & 2 & 9 & 3.5 & $1.37 \mathrm{E}-07$ & & \\
\hline \multirow[t]{3}{*}{ EST-06-03 } & 28 & 2 & 9 & 3.5 & $2.42 \mathrm{E}-07$ & & \\
\hline & & & & & $\beta_{-} i_{k}$ & $f_{-\mathrm{i} \_\mathrm{k}}$ & $\sigma_{f \_i k}$ \\
\hline & & & & & $1.67 \mathrm{E}-07$ & $0.126 \%$ & $\pm 0.020 \%$ \\
\hline \multicolumn{5}{|c|}{ Section $\# 4,12$ to 15 in. from the top } & \multicolumn{3}{|c|}{$\mathbf{R e}$} \\
\hline Sample ID & $\mathrm{X}$, in & $\mathrm{Y}$, in & $Z$, in & $\mathrm{H}_{\mathrm{k}}$, in. & $\beta_{\mathrm{i} k \mathrm{k} p}$ & & \\
\hline EST-04-06 & 8 & 2 & 12 & 3 & $2.16 \mathrm{E}-07$ & & \\
\hline EST-05-03 & 8 & 15 & 14 & 3 & $1.02 \mathrm{E}-07$ & & \\
\hline \multirow[t]{3}{*}{ EST-06-02 } & 28 & 2 & 15 & 3 & $1.77 \mathrm{E}-07$ & & \\
\hline & & & & & $\beta_{{ }_{i} \_\mathrm{k}}$ & $f_{-\mathrm{i} \_\mathrm{k}}$ & $\sigma_{\mathrm{f}_{\mathrm{i}} \mathrm{k}}$ \\
\hline & & & & & $1.65 \mathrm{E}-07$ & $0.107 \%$ & $\pm 0.017 \%$ \\
\hline \multicolumn{5}{|c|}{ Section \#5, Refractory Base } & \multicolumn{3}{|c|}{$\mathbf{R e}$} \\
\hline Sample ID & $\mathrm{X}$, in & $\mathrm{Y}$, in & $\mathrm{Z}$, in & $\mathrm{H}_{\mathrm{k}}$, in. & $\beta_{i \_k p}$ & & \\
\hline EST-04-07 & 8 & 2 & 17 & 4 & $1.95 \mathrm{E}-09$ & & \\
\hline \multirow[t]{4}{*}{ EST-06-01 } & 28 & 2 & 17 & 4 & $1.20 \mathrm{E}-08$ & & \\
\hline & & & & & $\beta_{-} i_{k}$ & $f_{-\mathrm{i} \_\mathrm{k}}$ & $\sigma_{f_{-} i k}$ \\
\hline & & & & & $6.98 \mathrm{E}-09$ & $0.005 \%$ & $\pm 0.001 \%$ \\
\hline & & & & & Total & $1.514 \%$ & $\pm 0.151 \%$ \\
\hline
\end{tabular}


To determine the soluble Re contained in the refractory sand from ES-31A, approximately $50 \%$ of the sand was removed, placed into a 55-gallon drum, mixed with DIW, and leached for several days. At the end of the leaching time, a sample of the leach solution was removed, filtered, and analyzed for Re using ICP-MS. The results show that the soluble fraction of Re contained in the sand for this test was $0.0032 \pm 0.0005 \%$ of the total Re in the test. Because soluble Re contribution from the sand in ES-31A was so small in comparison to the cast refractory block, other sand refractory samples were not considered a priority and have not been leached at the time this letter report was written.

\subsection{Extraction Results for ES-31B}

The second engineering scale test was ES31B. The main objective for this test was to obtain data that can be compared to a previous test conducted in FY03 using a simulated waste composition for tank 241-S-109 (Mahoney and Rassat 2003). Although a general description of the main objective for ES-31B has been provided above, the interested reader should consult the SAP (Sederburg and Thompson 2004) for additional details. In comparison, the total Re inventory in this test was approximately 18 times less than the inventory for ES-31A and -32A (Table 1). Twenty four refractory samples were used to determine the soluble Re and Cs. Using techniques as described in Section 3.1 and 3.2, the soluble fractions of Re and Cs were determined to

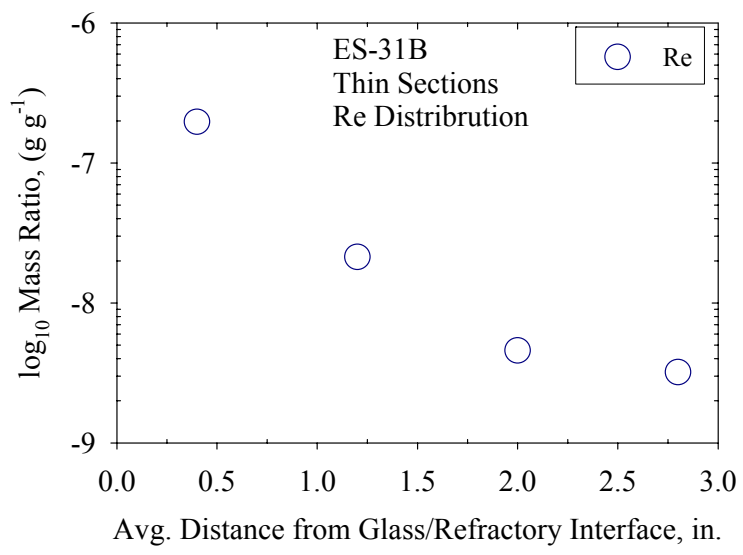

Figure 7. Re distribution as a function of depth for Thin Sections from ES-31B. be $0.771 \pm 0.063 \%$ and $0.084 \pm 0.006 \%$, respectively.

The results in Table 3 show that the soluble fraction of Re was a factor of 1.5 lower than ES$31 \mathrm{~A}$. The results also suggest that Re is evenly distributed along refractory wall sections, with a decrease in the Re concentration at the base which is different than the distribution seen in ES31A. Although it is unclear, experimental differences during ES-31A and ES-31B such as the loss of electrodes, feed rate differences, gas bubbles, soil caps, etc., could contribute to any differences in the results. It should also be noted that the Re distribution in these tests are estimated using samples that comprised less than $2.8 \%$ of the refractory mass.

As noted in Section 3.1, one additional sample in the ES-31B test was used to assess the Re penetration depth. This sample was sectioned (with out water cooling) along the y-axis into five individual pieces ( 0.7 -inch thick) using a miter saw with a 0.1 -inch thick diamond tip cutting blade. The extraction results are shown in Figure 7. These results are similar to those shown in Figure 6 for ES-31A. The dilute nitric acid-leachable Re concentration decreases by more than an order of magnitude with increasing distance away from the glass melt (Figure 7). No results were obtained for the outermost sample because extractions of that sample did not produce enough extract for analysis. 
Table 3. Soluble Fraction of Re and Cs contained in ES-31B.

\begin{tabular}{|c|c|c|c|c|c|c|c|c|c|c|}
\hline \multicolumn{5}{|c|}{ Section $\# 1,0$ to 4 in. from the top } & \multicolumn{3}{|c|}{$\mathbf{R e}$} & \multicolumn{3}{|c|}{ Cs } \\
\hline Sample ID & $X$, in & $\mathrm{Y}$, in & $\mathrm{Z}$, in & $\mathrm{H}_{\mathrm{k}}$, in. & ${ }^{a} \beta_{i k p}$ & & & $\beta_{\mathrm{ikp}}$ & & \\
\hline EST-07-01 & 8 & 2 & 2 & 4 & $1.34 \mathrm{E}-08$ & & & $4.76 \mathrm{E}-10$ & & \\
\hline EST-08-01 & 8 & 15 & 2 & 4 & $1.11 \mathrm{E}-08$ & & & $8.66 \mathrm{E}-10$ & & \\
\hline EST-07-05-1 & 2 & 5 & 2 & 4 & $1.77 \mathrm{E}-08$ & & & $1.65 \mathrm{E}-09$ & & \\
\hline EST-07-05-3 & 2 & 6 & 2 & 4 & $7.31 \mathrm{E}-09$ & & & $4.32 \mathrm{E}-10$ & & \\
\hline EST-08-05 & 2 & 12 & 2 & 4 & $2.13 \mathrm{E}-08$ & & & $5.60 \mathrm{E}-10$ & & \\
\hline \multirow[t]{3}{*}{ EST-09-01 } & 28 & 2 & 2 & 4 & $8.83 \mathrm{E}-09$ & & & $1.94 \mathrm{E}-10$ & & \\
\hline & & & & & ${ }^{\mathrm{a}} \beta_{-}{ }_{\mathrm{i} \_\mathrm{k}}$ & ${ }^{\mathrm{b}} f_{-\mathrm{i} i \mathrm{k}}$ & ${ }^{\mathrm{b}} \sigma_{\mathrm{f} \_\mathrm{i} \_\mathrm{k}}$ & 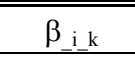 & $f_{\text {i_k }}$ & 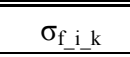 \\
\hline & & & & & $1.33 \mathrm{E}-08$ & $0.215 \%$ & $\pm 0.033 \%$ & $6.96 \mathrm{E}-10$ & $0.018 \%$ & $\pm 0.003 \%$ \\
\hline \multicolumn{5}{|c|}{ Section $\# 2,4$ to 8 in. from the top } & \multicolumn{3}{|c|}{$\overline{\operatorname{Re}}$} & \multicolumn{3}{|c|}{$\overline{C s}$} \\
\hline Sample ID & $\mathrm{X}$, in & $\mathrm{Y}$, in & $Z$, in & $\mathrm{H}_{\mathrm{k}}$, in. & $\beta_{\mathrm{i} k \mathrm{p}}$ & & & $\beta_{\mathrm{i} k \mathrm{k}}$ & & \\
\hline EST-07-02 & 8 & 2 & 6 & 4 & $7.11 \mathrm{E}-09$ & & & $1.93 \mathrm{E}-10$ & & \\
\hline EST-08-02 & 8 & 15 & 6 & 4 & $1.02 \mathrm{E}-08$ & & & $1.26 \mathrm{E}-10$ & & \\
\hline EST-07-06 & 2 & 5 & 6 & 4 & $1.19 \mathrm{E}-08$ & & & $2.75 \mathrm{E}-10$ & & \\
\hline EST-08-06-01 & 2 & 12 & 6 & 4 & $1.07 \mathrm{E}-08$ & & & $2.52 \mathrm{E}-10$ & & \\
\hline EST-08-06-02 & 4 & 13 & 6 & 4 & $5.89 \mathrm{E}-09$ & & & $7.81 \mathrm{E}-11$ & & \\
\hline \multirow[t]{3}{*}{ EST-09-02 } & 28 & 2 & 6 & 4 & $8.82 \mathrm{E}-09$ & & & $6.24 \mathrm{E}-10$ & & \\
\hline & & & & & $\beta_{\mathrm{ik}}$ & $\overline{f_{\mathrm{i} \_\mathrm{k}}}$ & $\overline{\sigma_{\mathrm{f}} \mathrm{i} \text {. }}$ & $\beta_{\mathrm{ik}}$ & $\overline{f_{\mathrm{i} \_\mathrm{k}}}$ & $\overline{\sigma_{\mathrm{f} \_\mathrm{i} k}}$ \\
\hline & & & & & $9.10 \mathrm{E}-09$ & $0.147 \%$ & $\pm 0.023 \%$ & $2.58 \mathrm{E}-10$ & $0.007 \%$ & $\pm 0.001 \%$ \\
\hline \multicolumn{5}{|c|}{ Section \#3, 8 to 13 in. from the top } & \multicolumn{3}{|c|}{$\mathbf{R e}$} & \multicolumn{3}{|c|}{ Cs } \\
\hline Sample ID & $\mathrm{X}$, in & $\mathrm{Y}$, in & $\mathrm{Z}$, in & $\mathrm{H}_{\mathrm{k}}$, in. & $\beta_{\mathrm{i} k \mathrm{p}}$ & & & $\beta_{i k p}$ & & \\
\hline EST-07-03 & 8 & 2 & 10.5 & 5 & $1.17 \mathrm{E}-08$ & & & $9.00 \mathrm{E}-10$ & & \\
\hline EST-08-03 & 8 & 15 & 10.5 & 5 & $1.82 \mathrm{E}-08$ & & & $1.17 \mathrm{E}-09$ & & \\
\hline EST-08-07 & 2 & 12 & 10.5 & 5 & $1.95 \mathrm{E}-08$ & & & $1.48 \mathrm{E}-10$ & & \\
\hline \multirow[t]{3}{*}{ EST-09-03 } & 28 & 2 & 10.5 & 5 & $9.67 \mathrm{E}-09$ & & & $9.69 \mathrm{E}-10$ & & \\
\hline & & & & & $\overline{\beta_{i k}}$ & $\overline{f_{\mathrm{i} \text { ik }}}$ & $\overline{\sigma_{\mathrm{f} \_\mathrm{i}} \mathrm{k}}$ & $\overline{\beta_{\mathrm{i} k \mathrm{k}}}$ & $\overline{f_{\mathrm{i} \text { ik }}}$ & $\overline{\sigma_{\mathrm{f} i \mathrm{i}} \mathrm{k}}$ \\
\hline & & & & & $1.48 \mathrm{E}-08$ & $0.300 \%$ & $\pm 0.046 \%$ & $7.98 \mathrm{E}-10$ & $0.026 \%$ & $\pm 0.004 \%$ \\
\hline \multicolumn{5}{|c|}{ Section \#4, 13 to 15 in. from the top } & \multicolumn{3}{|c|}{$\operatorname{Re}$} & \multicolumn{3}{|c|}{ Cs } \\
\hline Sample ID & $\mathrm{X}$, in & $\mathrm{Y}$, in & $\mathrm{Z}$, in & $\mathrm{H}_{\mathrm{k}}$, in & $\beta_{\mathrm{i} k \mathrm{p}}$ & & & $\beta_{\mathrm{i} k \_p}$ & & \\
\hline EST-07-04 & 8 & 2 & 14 & 2 & $8.41 \mathrm{E}-09$ & & & $7.14 \mathrm{E}-10$ & & \\
\hline EST-07-08 & 2 & 5 & 14 & 2 & $9.41 \mathrm{E}-09$ & & & $9.17 \mathrm{E}-10$ & & \\
\hline EST-08-04 & 8 & 15 & 14 & 2 & $3.37 \mathrm{E}-09$ & & & $8.83 \mathrm{E}-10$ & & \\
\hline EST-08-08 & 2 & 12 & 14 & 2 & $2.52 \mathrm{E}-08$ & & & $2.85 \mathrm{E}-10$ & & \\
\hline \multirow[t]{3}{*}{ EST-09-04 } & 28 & 2 & 14 & 2 & $6.65 \mathrm{E}-09$ & & & $8.12 \mathrm{E}-10$ & & \\
\hline & & & & & $\overline{\beta_{\mathrm{i} k \mathrm{k}}}$ & $\overline{f_{\mathrm{i} i \mathrm{k}}}$ & 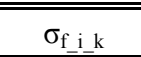 & $\bar{\beta} \beta_{\mathrm{i} k \mathrm{k}}$ & $\bar{f} f_{\mathrm{i} \_\mathrm{k}}$ & $\overline{\sigma_{\mathrm{f} \_\mathrm{i} k}}$ \\
\hline & & & & & $1.06 \mathrm{E}-08$ & $0.086 \%$ & $\pm 0.013 \%$ & $7.22 \mathrm{E}-10$ & $0.009 \%$ & $\pm 0.001 \%$ \\
\hline \multicolumn{5}{|c|}{ Section \#5, Refractory Base } & \multicolumn{3}{|c|}{$\operatorname{Re}$} & \multicolumn{3}{|c|}{ Cs } \\
\hline Sample ID & $\mathrm{X}$, in & $\mathrm{Y}$, in & $\mathrm{Z}$, in & $\mathrm{H}_{\mathrm{k}}$, in & $\beta_{i \_k p}$ & & & $\beta_{i \_k p}$ & & \\
\hline EST-07-09 & 8 & 2 & 17 & 4 & $3.50 \mathrm{E}-09$ & & & $1.35 \mathrm{E}-09$ & & \\
\hline EST-08-09 & 8 & 15 & 17 & 4 & $1.50 \mathrm{E}-09$ & & & $1.11 \mathrm{E}-09$ & & \\
\hline \multirow[t]{3}{*}{ EST-09-05 } & 28 & 2 & 17 & 4 & $7.17 \mathrm{E}-10$ & & & $1.38 \mathrm{E}-09$ & & \\
\hline & & & & & $\overline{\beta_{i k}}$ & $\overline{f_{\mathrm{i} \text { k }}}$ & $\overline{\sigma_{\mathrm{f} i \mathrm{k}}}$ & $\overline{\beta_{\mathrm{ink}}}$ & $\overline{f_{\mathrm{i} \text { k }}}$ & $\overline{\sigma_{\mathrm{f} i \mathrm{i}}}$ \\
\hline & & & & & $1.90 \mathrm{E}-09$ & $0.023 \%$ & $\pm 0.004 \%$ & $1.28 \mathrm{E}-09$ & $0.025 \%$ & $\pm 0.004 \%$ \\
\hline & & & & & Total & $0.771 \%$ & $\pm 0.063 \%$ & Total & $0.084 \%$ & $\pm 0.006 \%$ \\
\hline
\end{tabular}




\subsection{Extraction Results for ES-32A}

ES-32A was conducted using a waste simulant composition that contained both Re, and ${ }^{99} \mathrm{Tc}$ spikes. For a detailed discussion of this test the interested reader should consult the SAP (Sederburg and Thompson 2004). In general, the objective of this test was to compare these results to a similar test conducted in FY03 that contained ${ }^{99} \mathrm{Tc}$ in the waste simulant. ES-32A was used to determine the soluble fraction of Re and ${ }^{99} \mathrm{Tc}$ as well as the Re to ${ }^{99} \mathrm{Tc}$ volatilization ratio. One cast refractory sample from each horizontal slice (see Figure 3), obtained from the back wall near the exhaust port, was removed and extracted to determine the soluble fraction of Re and ${ }^{99}$ Tc. Table 4 shows the dilute nitric acid soluble fraction for each of the five sections in ES-32A. Applying Equations (1) through (12) to these results, the soluble fraction of Re and ${ }^{99} \mathrm{Tc}$ was determined to be $1.550 \pm 0.122$ and $0.367 \pm 0.029 \%$, respectively. The distribution of $\mathrm{Re}$ and ${ }^{99} \mathrm{Tc}$ in the different sections generally appears to be relatively uniform.

The ${ }^{99} \mathrm{Tc} / \mathrm{Re}$ volatilization ratio $\alpha_{k}$ was determined for each $k^{\text {th }}$ section using Equation(13).

$$
\alpha_{k}=\frac{\left(m_{T c, k} / m_{\text {total }, T c}\right)}{\left(m_{R e, k} / m_{\text {total }, R e}\right)}
$$

The volatilization ratio differed for each $k^{\text {th }}$ section, $0.14 \pm 0.03,0.21 \pm 0.05,0.41 \pm 0.09$, $0.93 \pm 0.22$, and $0.11 \pm 0.03$, for sections $1,2,3,4$, and 5 , respectively. The average ${ }^{99} \mathrm{Tc} / \mathrm{Re}$ volatilization ratio for ES-32A was $0.22 \pm 0.03$, excluding section 4 which was considered an outlier because it was $>5 \sigma$ away from the average. This average volatilization ratio determined from levels in the CRB is higher than the 0.06 value determined from FY03 scoria layer samples (McGrail et al. 2003b) but is similar to the 0.23 value determined from FY03 sand layer samples (Thompson 2003). 
Table 4. Soluble Fraction of Re and ${ }^{99} \mathrm{Tc}$ contained in ES-32A.

\begin{tabular}{|c|c|c|c|c|c|c|c|c|c|c|}
\hline \multicolumn{5}{|c|}{ Section \#1, 0 to 4 in. from the top } & \multicolumn{3}{|c|}{$\operatorname{Re}$} & \multicolumn{3}{|c|}{${ }^{99} \mathrm{Tc}$} \\
\hline Sample ID & $\mathrm{X}$, in & $\mathrm{Y}$, in & $\mathrm{Z}$, in & $\mathrm{H}_{\mathrm{k}}$, in. & ${ }^{a} \beta_{i k p}$ & ${ }^{\mathrm{b}} f_{\mathrm{i} i \mathrm{k}}$ & ${ }^{\mathrm{b} \sigma_{\mathrm{f}_{\mathrm{i} i k}}}$ & ${ }^{a} \beta_{i k p}$ & ${ }^{\mathrm{b}_{f_{\mathrm{i} i \mathrm{k}}}}$ & ${ }^{\mathrm{b} \sigma_{f_{-i} k}}$ \\
\hline EST-10-1A & 8 & 2 & 2 & 4 & 4.65E-07 & $0.414 \%$ & $\pm 0.068 \%$ & $3.29 \mathrm{E}-09$ & $0.058 \%$ & $\pm 0.009 \%$ \\
\hline \multicolumn{5}{|c|}{ "Section $\# 2,4$ to 8 in. from the top } & \multicolumn{3}{|c|}{$\overline{\mathrm{Re}}$} & \multicolumn{3}{|c|}{ 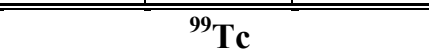 } \\
\hline Sample ID & $\mathrm{X}$, in & $Y$, in & $Z$, in & $\mathrm{H}_{\mathrm{k}}$, in. & $\beta_{i k p}$ & $f_{\mathrm{i} \_\mathrm{k}}$ & $\sigma_{f_{i} i k}$ & $\beta_{i k p}$ & $f_{\mathrm{i} i \mathrm{k}}$ & $\sigma_{\mathrm{f} i \mathrm{k}}$ \\
\hline EST-10-1B & 8 & 2 & 6 & 4 & $3.38 \mathrm{E}-07$ & $0.301 \%$ & $\pm 0.049 \%$ & 3.54E-09 & $0.062 \%$ & $\pm 0.010 \%$ \\
\hline \multicolumn{5}{|c|}{ Section \#3, 8 to 12 in. from the top } & \multicolumn{3}{|c|}{$\overline{\mathbf{R e}}$} & \multicolumn{3}{|c|}{$\overline{9} \mathbf{9 9} \mathrm{Tc}$} \\
\hline Sample ID & $\mathrm{X}$, in & $\mathrm{Y}$, in & $Z$, in & $\mathrm{H}_{\mathrm{k}}$, in. & $\beta_{\mathrm{ikp}}$ & $f_{\mathrm{i} \_\mathrm{k}}$ & $\sigma_{f_{-i k}}$ & $\beta_{i k p}$ & $f_{\mathrm{i} \_\mathrm{k}}$ & $\sigma_{\mathrm{f} i \mathrm{i}}$ \\
\hline EST-10-02 & 8 & 2 & 10 & 4 & $3.59 \mathrm{E}-07$ & $0.319 \%$ & $\pm 0.050 \%$ & 7.53E-09 & $0.132 \%$ & $\pm 0.021 \%$ \\
\hline \multicolumn{5}{|c|}{ Section $\# 4,12$ to 15 in. from the top } & \multicolumn{3}{|c|}{$\operatorname{Re}$} & \multicolumn{3}{|c|}{ ${ }^{99} \mathrm{Te}$} \\
\hline Sample ID & $\mathrm{X}$, in & $\mathrm{Y}$, in & $\mathrm{Z}$, in & $\mathrm{H}_{\mathrm{k}}$, in. & $\beta_{\mathrm{i} k p}$ & $f_{\text {i } \_k}$ & $\sigma_{f_{-}{ }_{i} k}$ & $\beta_{\mathrm{ik} p \mathrm{p}}$ & $f_{I_{i} \mathrm{k}}$ & $\sigma_{f_{-}{ }_{i} k}$ \\
\hline EST-10-03 & 8 & 2 & 13.5 & 3 & $1.04 \mathrm{E}-07$ & $0.069 \%$ & $\pm 0.011 \%$ & 4.89E-09 & $0.064 \%$ & $\pm 0.011 \%$ \\
\hline \multicolumn{5}{|c|}{ Section \#5, Refractory Base } & \multicolumn{3}{|c|}{$\operatorname{Re}$} & \multicolumn{3}{|c|}{${ }^{999} \mathrm{Tc}$} \\
\hline Sample ID & $X$, in & $Y$, in & $Z$, in & $\mathrm{H}_{\mathrm{k}}$, in. & $\beta_{\mathrm{i} k \mathrm{k} p}$ & $f_{\perp_{i} \mathrm{k}}$ & $\sigma_{f_{-} \_k}$ & $\beta_{\mathrm{i} k \mathrm{k}}$ & $f_{\mathrm{i}_{-} \mathrm{k}}$ & $\sigma_{f_{-}{ }_{i} k}$ \\
\hline \multirow[t]{2}{*}{ EST-10-04 } & 8 & 2 & 17 & 4 & $6.74 \mathrm{E}-07$ & $0.446 \%$ & $\pm 0.072 \%$ & 3.92E-09 & $0.051 \%$ & $\pm 0.008 \%$ \\
\hline & & & & & Total & $1.550 \%$ & $\pm 0.122 \%$ & Total & $0.367 \%$ & $\pm 0.029 \%$ \\
\hline
\end{tabular}




\subsection{Summary}

This report documents the testing that has been completed to date on engineered-scale tests of the new $\mathrm{BV}$ process and waste package design. The test data have been reduced to estimate the amount of $\mathrm{Cs}, \mathrm{Re}$, and ${ }^{99} \mathrm{Tc}$ that can be leached from the BV cast refractory block. Thinsection samples illustrated that majority of the Re will be concentrated in the first 0.7 in of the refractory.

A summary of the relative fraction of soluble Re contained in the BV castable refractory for ES-31A, $-31 \mathrm{~B}$, and $-32 \mathrm{~A}$, along with the ${ }^{99} \mathrm{Tc}$ results from ES-32A are shown in Figure 8. The fraction of the total for each $k^{\text {th }}$ section was computed by dividing the soluble fraction for each section by the total amount. For example, a value of 0.71 was computed for ES-31A section \#1 by dividing $0.838 \%$, which is the $\%$ soluble in section $\# 1$, by the total amount, $1.514 \%$. A comparison of these results illustrates that there is some variability among each ES test (Figure 8). For example, in ES-31A, greater than $55 \%$ of the total soluble Re is contained within the top 5 inches of the refractory wall, but for the same section in ES-31B and -32A the total soluble Re is 27.9 and $26.7 \%$, respectively. This observed variability in the relative fraction of soluble Re contained in each $k^{\text {th }}$ section for the individual ES test, may be caused by fluctuations in process temperature which occurred during each melt.

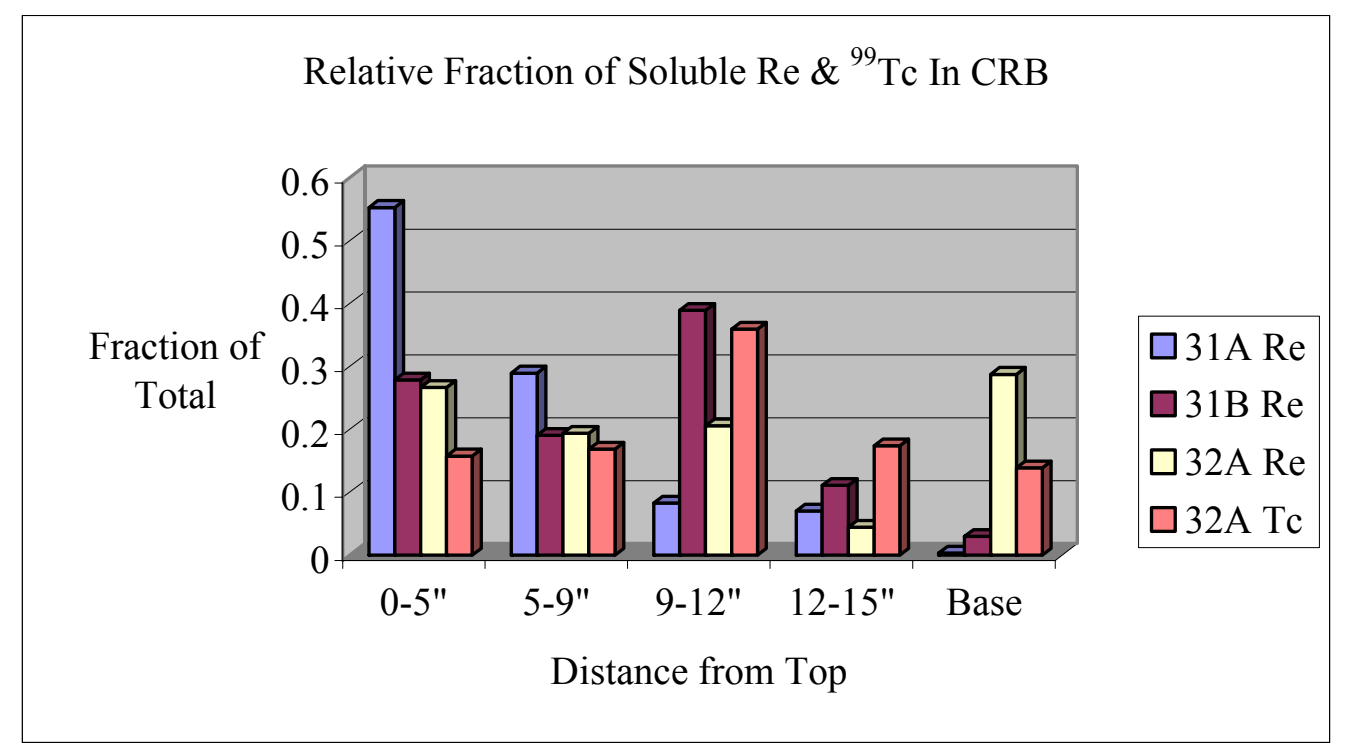

Figure 8. Summary of ES-31A, -31B, and -32A Extraction Results. 
In these dynamic ES tests, several factors contribute to the deposition of Re and $/$ or ${ }^{99} \mathrm{Tc}$ on the CRB and box lid. These factors include: 1) horizontal and vertical temperature gradients in the $\mathrm{CRB}, 2$ ) air-flow, 3) physical and chemical changes in the CRB, and 4) mineralogical phase changes the CRB undergoes during the BV process (Kim et al. 2004). Results from the individual ES tests suggest the following with regard to ${ }^{99} \mathrm{Tc}$ deposition into the pores of the CRB 1) deposition into the pores of the CRB is probably occurring by vapor phase transport and molten salt intrusion, although the rate-limiting mechanism is not clear and 2) $\mathrm{Cs}, \mathrm{Re}$, and ${ }^{99} \mathrm{Tc}$ are being deposited in the CRB in a leachable form. This information will be used to assess progress to date and guide development of additional modifications to the $\mathrm{BV}$ process to further reduce the soluble ${ }^{99} \mathrm{Tc}$ levels in the BV waste package, as necessary. 


\subsection{Uncertainties}

Like all scientific studies there are limitations associated with the experimental and analytical methods, understanding of the fundamental processes, and assumptions made to allow for best estimates and conclusions to be drawn from limited data. The analyses and results provided in the preceding sections of this report are presented as though all the uncertainty is quantitatively reflected in the experimental and analytical uncertainty. Given the state of information and the complexity of the mechanisms involved, this representation of the overall uncertainty is incomplete. This section discusses, the limitations, key issues, and any assumptions that were made to reach the reported conclusions.

The initial purpose for determining the soluble fraction contained in the CRB was to identify whether or not a soluble salt of $\mathrm{Cs}$, Re, and/or ${ }^{99} \mathrm{Tc}$ was being deposited within the pore-spaces of the $\mathrm{CRB}$ as a result of the $\mathrm{BV}$ process. A primary objective was to ensure that the extraction and analysis procedure resulted in a low enough detection limit to demonstrate that Re and ${ }^{99} \mathrm{Tc}$ were below desired limits. Once sample extractions from ES-31A determined that Re was being deposited in the CRB, additional extractions were conducted to attempt to quantify the total amount of soluble Re present. In other words, the initial purpose was simply to detect the presence of Re, but the procedure evolved into a methodology to estimate the fraction of soluble salt contained within the entire CRB. The following assumptions were necessary to extrapolate the analytical results to obtain a soluble fraction estimate:

- Spatial Variability: An assumption was used that the average concentration, in grams per gram, of $\mathrm{Cs}, \mathrm{Re}$, or ${ }^{99} \mathrm{Tc}$ is evenly distributed throughout a horizontal section. In other words, any sample removed from a horizontal section is representative of the entire section. This assumption was based on the distributions observed in several ES tests, including ES-31A, which suggest greater horizontal than vertical symmetry. Although the horizontal symmetry was better, results from these ES tests indicate variability between individual samples taken from a given horizontal section as well as asymmetry between the air-inlet and exhaust ends of the BV waste package. The variability in the deposition of $\mathrm{Cs}, \mathrm{Re}$, and/or ${ }^{99} \mathrm{Tc}$ is thought to result from two possible mechanisms: molten salt penetration and volatilization/condensation of soluble salts. These two mechanisms along with the variability in test conditions contribute to the variability in both the vertical and horizontal distributions between tests. Testing and sampling of fullscale melts is planned and will determine if the spatial variability is as prominent at fullscale. 
- Process Variability: The current set of ES tests represent a limited range of process variability on the total soluble fraction in the CRB. Process variability includes 1) power level variations, 2) feed rate variations, 3) variation in melting durations, 4) horizontal and vertical temperature gradients in the CRB, 5) air-flow variations, and 6) physical and chemical changes in the CRB before and during the BV process. ES tests conducted to date represent a range of process conditions, but may not provide upper and lower boundaries for the full range of process conditions to be considered. Significant differences in salt deposition processes may occur at larger scales and these effects, if any, cannot be quantified from ES tests. Therefore, the range of expected process variability will need to be evaluated from analyses of up to 50 full-scale boxes planned for the demonstration bulk vitrification system.

- Extraction Methods: The extraction technique used in this study does not recover 100\% of the accessible soluble analytes. Moreover, differences in the recovery efficiency from sample to sample have not been evaluated. A scoping study using a $50 \mathrm{ppb}$ stock solution demonstrated that $>80 \%$ of the starting concentration was recovered after three consecutive extractions. However, the remaining contaminant is thought to be trapped in the smaller pores spaces which are not drained during the centrifugation step, which gives a small low bias in the results. The amount of pores that are not drained may vary from sample to sample based on the thermal history of different portions of the CRB and also likely contributes to some of the variability seen in the refractory results.

- $\quad$ Scale Differences: The extent that ES test results are representative of the general trends expected in the full-scale BV waste package are presently unknown. The ES and fullscale waste packages showed similar trends for the top-down melting configuration used in FY03 testing. However, no data from full scale bottom-up melts is currently available. The best estimate of the soluble fraction provided in this report is based on ES test results. This estimate does not account for the differences in scale between the ES and fullscale BV waste package that may affect the soluble fraction. For example, engineeringscale $\mathrm{BV}$ waste package has a $\mathrm{CRB} /$ glass weight ratio of 3 , where the full-scale package has a CRB/glass weight ratio of about 0.35 . The CRB thermal profiles of the ES and full scale packages may be very different and influence Re and ${ }^{99} \mathrm{Tc}$ deposition within the CRB. The surface area to volume ratio is also roughly $1 / 6$ lower in the full-scale system and may reduce the relative amount of material that migrates to the refractory/glass interface and deposits in the CRB. Full-scale testing results will be used to assess the scale-up relationship. 


\subsection{References}

Darab JG, and PA Smith. 1996. "Chemistry of Technetium and Rhenium Species During LowLevel Radioactive Waste Vitrification." Chem. Mater. 8: 1004-1021.

DOE. 2002. Performance Management Plan for the Accelerated Cleanup of the Hanford Site., DOE/RL-2002-47, U.S. Department of Energy, Richland, WA.

Kim DS, MJ Schweiger, RW Shimskey, JV Crum, GJ Sevigny, and ML Elliott. 2004. Letter Report: Soluble Fraction of Re and Tc in Engineering-Scale 31A, 31B, and 32A Tests, Rev. 0 (DVBS Activity ID: 32A515), Pacific Northwest National Laboratory, Richland, WA.

Kim DS, JD Vienna, PR Hrma, MJ Schweiger, J Matyas, JV Crum, DE Smith, GJ Sevigny, WC Buchmiller, JS Tixier, VJ Yeager, and KB Belew. 2003. Development and Testing of ICV Glasses for Hanford LAW., PNNL-14351, Pacific Northwest National Laboratory, Richland, WA.

Luey J, and DK Seiler. 1995. Application of In Situ Vitrification in the Soil Subsurface: Engineering-Scale Testing, PNL-10485, Pacific Northwest Laboratory, Richland, WA.

Mahoney LA, and SD Rassat. 2003. Tank 241-S-109 Cold Saltcake Simulant Formulation, Letter Report ST04.007, Pacific Northwest National Laboratory, Richland, WA.

Mann FM, BP McGrail, DH Bacon, RJ Serne, KM Krupka, RJ Puigh, R Khaleel, and S Finfock. 2003. Risk Assessment Supporting the Decision on the Initial Selection of Supplemental ILAW Technologies, RPP-17675, Rev. 0, CH2MHILL Hanford Group Inc., Richland, WA.

McGrail BP, DH Bacon, RJ Serne, and EM Pierce. 2003a. A Strategy to Assess Performance of Selected Low-Activity Waste Forms in an Integrated Disposal Facility, PNNL-14362, Pacific Northwest National Laboratory, Richland, WA.

McGrail BP, EM Pierce, HT Schaef, EA Rodriguez, JL Steele, AT Owen, and DW Wellman. 2003b. Laboratory Testing of Bulk Vitrified and Steam Reformed Low-Activity Waste Forms to Support A Preliminary Risk Assessment for an Integrated Disposal Facility., PNNL-14414, Pacific Northwest National Laboratory, Richland, WA.

Sederburg P, and L Thompson. 2004. Quantitative Engineering Scale Testing Plan, 17902-ESRT1, Rev.1, AMEC Earth and Environmental, Inc. GeoMelt Division, Richland, WA.

Thompson L. 2003. Bulk Vitrification Project \#17902 Engineering-Scale In-Container Vitrification Test Results - Final Report, AMEC Earth and Environmental, Inc. - GeoMelt Division, Richland, WA.

Tixier JS, J. A. Stottlemyre, and M. T. Murphy. 1991. "Vitrified Underground Barriers." Waste Management 91: 603-611. 
Wolery TJ. 1992. EQ3NR, A Computer Program for Geochemical Aqueous SpeciationSolubility Calculations: Theoretical Manual, User's Guide, and Related Documentation (Version 7.0), UCRL-MA-110662 PT III, Lawrence Livermore National Laboratory, Livermore, CA. 


\subsection{Appendix A: Soluble Fraction Error Calculation}

Determining the experimental uncertainty of the soluble fraction calculation takes into account uncertainties of each parameter in Equation (1) through (12). For uncorrelated random errors, the standard deviation of a function $f\left(x_{1}, x_{2}, \ldots \ldots, x_{n}\right)$ is given by:

$$
\sigma_{f}=\sqrt{\sum_{i=1}^{n}\left(\frac{\partial f}{d x_{i}}\right)^{2} \sigma_{i}^{2}}
$$

where $\sigma_{f}$ is the standard deviation of the function $f, x_{i}$ is parameter $i$, and $\sigma_{i}$ is the standard deviation of parameter $i$. The uncertainties resulting from propagation of error for Equation (1) through (12) are given in Equations (15) through (26), respectively.

$$
\begin{aligned}
& \sigma_{m_{i, k, p, q}}=\left[\sum_{n=1}^{N_{e x r, k, p, q}} m_{i, k, p, q, n}^{2} \cdot\left[\left(\frac{\sigma_{C_{i, k, p, q, n}}}{C_{i, k, p, q, n}}\right)^{2}+\left(\frac{\sigma_{V_{k, p, q, n}}}{V_{k, p, q, n}}\right)^{2}\right]^{\frac{1}{2}}\right. \\
& \sigma_{m_{\text {refract }, k, p}}=\left[\sum_{q=1}^{N_{\text {fragment }, k, p}} \sigma_{m_{\text {refract }, k, p, q, 1}^{2}}^{2}\right]^{\frac{1}{2}} \\
& \sigma_{m_{i, k, p}}=\left[\sum_{q=1}^{N_{\text {fragment }, k, p}} \sigma_{m_{i, k, p, q}}^{2}\right]^{\frac{1}{2}} \\
& \sigma_{\beta_{i, k, p}}=\beta_{i, k, p} \cdot\left[\left(\frac{\sigma_{m_{i, k, p}}}{m_{i, k, p}}\right)^{2}+\left(\frac{\sigma_{m_{\text {refract }, k, p}}}{m_{\text {refract }, k, p}}\right)^{2}\right]^{\frac{1}{2}} \\
& \sigma_{\beta_{i, k}}=\frac{1}{N_{\text {samples }, k}} \cdot\left[\sum_{p=1}^{N_{\text {samples }, k}} \sigma_{\beta_{i, k, p}}^{2}\right]^{\frac{1}{2}} \\
& \sigma_{A_{\text {outer }}}=\left[\left(L_{1} \cdot W_{1}\right)^{2} \cdot\left(\left(\frac{\sigma_{L_{1}}}{L_{1}}\right)^{2}+\left(\frac{\sigma_{W_{1}}}{W_{1}}\right)^{2}\right)+\left(2 \cdot C_{1}^{2}\right)^{2} \cdot 2^{2} \cdot\left(\frac{\sigma_{C_{1}}}{C_{1}}\right)^{2}\right]^{\frac{1}{2}} \\
& \sigma_{A_{\text {inner }}}=\left[\left(L_{2} \cdot W_{2}\right)^{2} \cdot\left(\left(\frac{\sigma_{L_{2}}}{L_{2}}\right)^{2}+\left(\frac{\sigma_{W_{2}}}{W_{2}}\right)^{2}\right)+\left(2 \cdot C_{2}^{2}\right)^{2} \cdot 2^{2} \cdot\left(\frac{\sigma_{C_{2}}}{C_{2}}\right)^{2}\right]^{\frac{1}{2}} \\
& \sigma_{V_{k}}=V_{k} \cdot\left[\left(\frac{\sigma_{A_{\text {outer }}}^{2}+\sigma_{A_{\text {inner }}}^{2}}{\left(A_{\text {outer }}-A_{\text {inner }}\right)^{2}}\right)+\left(\frac{\sigma_{H_{k}}}{H_{k}}\right)^{2}\right]^{\frac{1}{2}} \quad \text { for sections in the wall }(\mathrm{k}=1 \text { to 4) }
\end{aligned}
$$




$$
\begin{gathered}
\sigma_{V_{k}}=V_{k} \cdot\left[\left(\frac{\sigma_{A_{\text {inner }}}}{A_{\text {inner }}}\right)^{2}+\left(\frac{\sigma_{H_{k}}}{H_{k}}\right)^{2}\right]^{\frac{1}{2}} \text { for the base section }(\mathrm{k}=5) \\
\sigma_{m_{i, k}}=m_{i, k} \cdot\left[\left(\frac{\sigma_{\beta_{i, k}}}{\beta_{i, k}}\right)^{2}+\left(\frac{\sigma_{V_{k}}}{V_{k}}\right)^{2}+\left(\frac{\sigma_{\rho_{\text {refract }}}}{\rho_{\text {refract }}}\right)^{2}\right]^{\frac{1}{2}} \\
\sigma_{f_{i, k}}=f_{i, k} \cdot\left[\left(\frac{\sigma_{m_{i, k}}}{m_{i, k}}\right)^{2}+\left(\frac{\sigma_{m_{\text {total }, i}}}{m_{\text {total }, i}}\right)^{2}\right]^{\frac{1}{2}} \\
\sigma_{f_{\text {total }, i}}=f_{\text {total }, i}\left[\sum_{k=1}^{N_{\text {section }}}\left(\frac{\sigma_{f_{i, k}}}{f_{i, k}}\right)^{2}\right]^{\frac{1}{2}}
\end{gathered}
$$

Table 5. List of Relative Uncertainties for Measure Quantities

\begin{tabular}{|c|c|}
\hline \hline Quantity $(\mathbf{x})$ & Fractional Relative Uncertainty $\left(\boldsymbol{\sigma}_{\mathbf{x}} / \mathbf{x}\right)$ \\
\hline$C_{i, k, p, q, n}$ & 0.10 \\
\hline$V_{k, p, q, n}$ & 0.01 \\
\hline$m_{r e f r a c t, k, p, q, n}$ & 0.01 \\
\hline$L_{1}$ & 0.01 \\
\hline$W_{1}$ & 0.01 \\
\hline$C_{1}$ & 0.035 \\
\hline$L_{2}$ & 0.01 \\
\hline$W_{2}$ & 0.015 \\
\hline$C_{2}$ & 0.065 \\
\hline$H_{k}$ & 0.10 \\
\hline$\rho_{\text {refract }}$ & 0.05 \\
\hline$m_{\text {total }, i}$ & 0.10 \\
\hline
\end{tabular}

